\title{
The knowledge of the flora of Mexico
}

DOI: $10.17129 /$ botsci.1925 $\mathrm{n}$ this issue of Botanical Sciences commences the publication of a series of articles that will contribute to evaluate the current state of knowledge of the flora of Mexico, which has advanced in an important way since the middle of the twentieth century. This progress is based on a wide exploration of the field that derived, in the first instance, the development and consolidation of scientific collections (Herbariums and Botanical Gardens), in regional, state and national inventories, as well as in the formation of high quality human resources. Despite the above mentioned, the Flora of Mexico Project, an important work that will synthesize the knowledge about the plants in the country, remains a challenge not yet surpassed for Mexican botanists.

With the purpose of undertaking the fundamental role in this project that the Botanical Society of Mexico (SBM), as an association which brings together botanists interested in the knowledge of Mexican plants and has as one of its main objectives, as stated at its first meeting held on 23 June 1941, the following: ... "the study of the national Flora and the dissemination of knowledge concerning it, for its improved conservation and rational use of its resources ...", during the celebration of the XX Mexican Congress of Botany, and in commemoration of the 75 years of the founding of our society, two symposia were organized to synthesize the progress achieved so far in the knowledge of the flora registered until now in Mexico.

The first of symposium was entitled Regional Floristic Inventories of Mexico, in which the eight regional delegates of the SBM (2014-2016) were invited to coordinate an analysis and synthesis of the knowledge of the flora of the area that each one represented. The regional areas have a geographical delimitation that aims to promote the collaboration of the botanists of the country by grouping neighboring states. The article by González-Elizondo et al., which covers the northern region (Chihuahua, Coahuila, Nuevo León and Durango), is the first of the contributions to be published for this purpose. The second symposium was called Diverse Families of the Flora of Mexico, whose goal was to obtain an update on the state of the art of taxonomic knowledge of families with the greatest number of species present in the country and in order to accomplish this Mexican specialists were invited. This issue publishes references to Lamiaceae (Martínez-Gordillo et al.).

An important conclusion derived from these symposia, and which is embedded in the contributions mentioned, is that, despite the fundamental advances that have been given to the knowledge of the Mexican flora, our country still suffers from a pertinent and necessary floristic exploration in many areas of its territory, in addition many groups of plants have not been the subject of a taxonomic synthesis. The latter occurs even for families who have specialists, or already have a floristic treatment, because they require studies of taxonomic complexes not yet understood and/or updates that take into account changes arising from the advancement of taxonomic knowledge. Furthermore, there is an alarming shortage of taxonomists for the large number of families registered for Mexico. Taking into account the above mentioned and in ac- 
cordance with the editor of Botanical Sciences, Dr. Salvador Arias, we extend an enthusiastic invitation to botanists and taxonomic group specialists to submit contributions that will assist us to identify the floristic and taxonomic advances of the plants distributed in Mexico. We hope that the contributions that are published from this issue onward will be a stimulus to advancement in this relevant and urgent task.

Our recognition goes to the authors who participated in the symposiums and for their commitment to publish their contributions, which we are sure will make us reflect on the urgency to continue with the basic taxonomic work that is still required and that will allow, undoubtedly, a breakthrough in other areas of scientific knowledge that require the information provided by the floristic and taxonomic research of the Flora of Mexico. Finally, we thank the editorial team of this journal for their support in making this proposal a reality.

Sincerely,

Guillermo Ibarra Manríquez, Abisaí Josué García Mendoza, María Hilda Flores Olvera. 